\section{Yield Response of Watermelon and Muskmelon to L-Tryptophan Applied to Soil}

\author{
W.T. Frankenberger, Jr., and M. Arshad \\ Department of Soil and Environmental Sciences, University of California, \\ Riverside, CA 92521
}

Additional index words. agrochemicals, auxins, plant growth regulators, Citrullus lanatus, Cucumis melo

\begin{abstract}
This study was conducted to determine the influence of L-tryptophan (LTRP) applied to soil on the yield of two watermelon (Citrullus Lanatus L.) and one muskmelon (Cucumis melo L.) cultivars. Experiments were established in which L-TRP was applied to seedlings as a soil drench in the glasshouse ranging from $6 \times 10^{-5}$ to $60 \mathrm{mg} \cdot \mathrm{kg}^{-1}$ soil; the seedlings were transplanted into the field 2 weeks later. The application of L-TRP enhanced the cumulative weight of the melons $58 \%$ ('Royal Sweet' watermelon), $80 \%$ ('Royal Windsor' watermelon), and $42 \%$ ('Top Score' muskmelon) over their respective controls: the average weight per fruit was increased up to $43 \%$ for watermelon and $36 \%$ for muskmelon. No increase in yield was observed when LTRP was applied to the seedlings directly in the field, but only when added in contained systems 2 weeks before transplanting into the field. The increase in yield was due to a physiological response rather 'than a nutritional effect because of the low L-TRP concentrations applied.
\end{abstract}

L-Tryptophan (L-TRP), also known as B3-indolylalanine, is considered an essential amino acid to man, animals, and some bacteria (Lactobacillus arabinosus, L. casei, Streptococcus faecalis, and Leuconostoc mesenteroids) (Meister, 1965). Plants are capable of synthesizing TRP from 3-phosphoshikimic acid and subsequently chorismic acid and anthranilic acid (Lehninger, 1975). Several microorganisms release secondary metabolites upon the use of TRP. The release of auxins has been reported as a result of TRP metabolism in soil (Frankenberger and Brunner, 1983). Thimann (1935) was the first to demonstrate that TRP is a precursor of the plant hormone indole-3-acetic acid (IAA) when working with cultures of Rhizopus suinus. We recently demonstrated the conversion of L-TRP to IAA by a fluorescent pseudomonas isolated from a soilroot interface by ion suppression-high performance liquid chromatography (HPLC)-UV spectrometry (Frankenberger and Poth, 1987a). The isolation and detection of IAA as a secondary metabolize of L-TRP was also demonstrated from Pisolithus tinctorius (an ectomycorrhizal fungus) by thin-layer chromatography, HPLC, an enzyme-linked immunosorbent (monoclinal antibody) assay, and unequivocally identified by gas chromatography-mass spectrometry (Frankenberger and Poth, 1987b).

Received for publication 23 Apr. 1990. We thank UlrichKarlson and Karin Nieto for their assistance in the field and P.A. Hammer (Associate Editor for Statistics, Hortscience) for his advice on the statistical analysis of the data. The cost of publishing this paper was defrayed in part by the payment of page charges. Under postal regulations, this paper therefore must be hereby marked $a d$ vertisement solely to indicate this fact.
Tracer studies have demonstrated that TRP is metabolized to IAA in higher plants. Exogenously supplied $2-{ }^{14} \mathrm{C}$-DL-tryptophan incubated in watermelon tissue was incorporated into IAA (Dannenburg and Liverman, 1957). Dual-labeled experiments with ${ }^{14} \mathrm{C}$-labeled indole and ${ }^{3} \mathrm{H}$-serine added to pea seedlings confirmed that the indole was incorporated into IAA via TRP (Erdmann and Schiewer, 1971). Further work in our laboratory has established that the microbial pathway of IAA production with TRP serving as a precursor involves a transaminase reaction with the formation of indole-3-pyruvic acid as an intermediate (Frankenberger and Poth, 1988). Recently, we have reported that the application of TRP to soil affects the yield of radish, most likely due to TRP-derived auxins (Frankenberger et al., 1990). The objective of this study was to determine the effects of L-TRP applied as a soil additive on the yield of watermelon and muskmelon in the field.

This study was conducted at the Moreno harvests.
Valley Field Station, Univ. of California, in Summer 1987 on a Hanford sandy loam (coarse-loamy, mixed thermic Typic Xerorthent). Soil analyses indicated the following chemical and physical properties: $\mathrm{pH}$ 5.9; total N, $730 \mathrm{ppm}$; total P, $530 \mathrm{ppm}$; composition, sand $55 \%$, silt $29 \%$, and clay $16 \%$.

On 29 Apr. 1987, seeds of two watermelon cultivars, Royal Sweet and Royal Windsor, and a muskmelon, 'Top Score', were planted in flats of washed silica sand in a glasshouse to obtain uniform size. Temperatures ranged from $28 \mathrm{C}$ during the day to $\approx 19 \mathrm{C}$ at night. Ten days later, the seedlings were transplanted into cells containing the field soil $(50 \mathrm{~g}$ each). The seedlings were treated with Hoagland's mineral nutrient solution (one-half strength). On 19 May 1987, L-TRP (Sigma, St. Louis) (15 ml solution) was added as a soil drench at concentrations ranging from $10-{ }^{9}$ to $10-{ }^{3} \mathbf{M}\left(6 \times 10^{-5}\right.$ to $60 \mathrm{mg} \cdot \mathrm{kg}^{-1}$ soil). A control was treated with deionized water. On 2 June 1987 the seedlings were transplanted into the field.

The experimental layout was a completely randomized design with $6 \times 6 \mathrm{~m}$ spacing for the watermelon and $3 \times 3 \mathrm{~m}$ for the muskmelon with 15 replicates per treatment. Irrigation water was applied as furrow irrigation. The field was broadcast with ammonium nitrate $\left(100 \mathrm{~kg} \cdot \mathrm{ha}^{-1}\right)$ before planting. The yield was expressed in number of melons per plant and the cumulative weight of fruit per plant. The harvest schedule for the watermelon was as follows: 28 Sept., 26 Oct., and 20 Nov. (harvests 1, 2, and 3, respectively). Muskmelons were picked weekly starting from 14 Sept. throughout 28 Oct. with the data pooled into three harvests. Ripe watermelons were picked based on the dried curly tendril on the leaf near the stem. The muskmelon was considered mature when the fruit changed from green to yellow (tan) and an abscission layer formed between the stem and fruit. The data in each harvest were subjected to an analysis of variance and means of L-TRP treatments were compared with the control according to Dunnett's test. Regression analyses were performed on the treatments excluding the control (Steel and Torrie, 1980). Fruit size (kg/fruit) was determined by dividing the mean fruit yield per plant by the mean number of fruit per plant for each

Table 1. Cumulative yield of 'Royal Windsor' watermelon in response to L-tryptophan during three

\begin{tabular}{|c|c|c|c|c|c|c|c|c|}
\hline \multirow{4}{*}{$\begin{array}{l}\text { L-Tryptophan } \\
\text { (mg.kg-1 soil) }\end{array}$} & \multicolumn{8}{|c|}{ Fruit } \\
\hline & \multicolumn{3}{|c|}{ No./plant } & \multicolumn{3}{|c|}{ Total fresh wt/plant $(\mathrm{kg})$} & \multirow{3}{*}{\multicolumn{2}{|c|}{$\begin{array}{c}\text { Size } \\
(\mathrm{kg} / \mathrm{fruit})^{2}\end{array}$}} \\
\hline & \multicolumn{6}{|c|}{ Harvest } & & \\
\hline & 1 & 2 & 3 & 1 & 2 & 3 & & \\
\hline Control & 0.6 & 2.6 & 3.8 & 1.7 & 15.1 & 20.5 & 5.39 & \\
\hline 60 & 1.3 & 3.3 & 4.5 & 3.6 & 22.1 & 28.2 & 6.27 & $(16 \%)$ \\
\hline 6.0 & 0.8 & 2.8 & 4.1 & 1.9 & 24.1 & 31.2 & 7.61 & $(41 \%)$ \\
\hline $6.0 \times 10^{-1}$ & 1.1 & 3.0 & 4.4 & 5.2 & 23.3 & 30.2 & 6.86 & $(27 \%)$ \\
\hline $6.0 \times 10^{-2}$ & $1.9^{*}$ & 4.1 & 5.3 & 4.4 & 28.4 & 33.7 & 6.36 & $(18 \%)$ \\
\hline $6.0 \times 10^{-3}$ & 0.8 & 3.5 & 5.0 & 3.3 & 24.6 & 31.5 & 6.30 & $(17 \%)$ \\
\hline $6.0 \times 10^{-4}$ & 1.4 & 3.7 & 5.1 & 5.7 & 27.1 & $34.5^{*}$ & 6.76 & $(25 \%)$ \\
\hline $6.0 \times 10^{-5}$ & 1.2 & 3.6 & 5.2 & 2.4 & $29.2^{*}$ & $36.9^{*}$ & 7.10 & $(32 \%)$ \\
\hline
\end{tabular}

${ }^{ }$Figures in parenthesis indicate percent increase over the control.

*Means significantly different from control at $P=0.05$, according to Dunnett's test. 
Table 2. Cumulative yield of 'Royal Sweet' watermelon in response to L-tryptophan during three harvests.

\begin{tabular}{|c|c|c|c|c|c|c|c|c|}
\hline \multirow{4}{*}{$\begin{array}{l}\text { L-Tryptophan } \\
\text { (mg } \cdot \mathrm{kg}^{-1} \text { soil) }\end{array}$} & \multicolumn{8}{|c|}{ Fruit } \\
\hline & \multicolumn{3}{|c|}{ No./plant } & \multicolumn{3}{|c|}{ Total fresh wt/plant $(\mathrm{kg})$} & \multirow{3}{*}{\multicolumn{2}{|c|}{$\begin{array}{c}\text { Size } \\
\text { (kg/fruit) }^{z}\end{array}$}} \\
\hline & \multicolumn{6}{|c|}{ Harvest } & & \\
\hline & 1 & 2 & 3 & 1 & 2 & 3 & & \\
\hline Control & 1.1 & 2.7 & 3.7 & 5.3 & 18.6 & 26.9 & 7.27 & \\
\hline 60 & $2.8^{\star}$ & 4.3 & 5.1 & $18.9^{*}$ & $34.0^{*}$ & 37.0 & 7.25 & $(0 \%)$ \\
\hline 6.0 & 1.1 & 3.3 & 4.5 & 6.6 & 30.2 & 34.8 & 7.73 & $(6 \%)$ \\
\hline $6.0 \times 10^{-1}$ & 1.4 & 4.3 & 4.8 & 11.4 & 32.1 & 36.2 & 7.54 & $(4 \%)$ \\
\hline $6.0 \times 10^{-2}$ & 1.4 & 3.3 & 3.9 & 8.9 & 29.9 & 34.2 & 8.77 & $(21 \%)$ \\
\hline $6.0 \times 10^{-3}$ & 1.4 & 3.3 & 4.4 & 10.6 & $33.0^{*}$ & 40.6 & 9.23 & $(27 \%)$ \\
\hline $6.0 \times 10^{-4}$ & 1.7 & 4.0 & 5.4 & 11.3 & $32.8^{*}$ & 39.6 & 7.33 & $(1 \%)$ \\
\hline $6.0 \times 10^{-5}$ & $2.5^{*}$ & $4.7^{*}$ & $5.5^{*}$ & 14.2 & $38.5^{*}$ & $42.6^{*}$ & 7.75 & $(7 \%)$ \\
\hline
\end{tabular}

${ }^{2}$ Figures in parenthesis indicate percent increase over control.

* Means significantly different from control at $P=0.05$, according to Dunnett's test.

Table3. Cumulative yield of 'Top Score' muskmelon in response to L-tryptophan during three barvests.

\begin{tabular}{|c|c|c|c|c|c|c|c|c|c|c|}
\hline \multirow{4}{*}{$\begin{array}{l}\text { L-Tryptophan } \\
(\mathrm{mg} \cdot \mathrm{kg}\end{array}$} & & \multicolumn{9}{|c|}{ Fruit } \\
\hline & & \multicolumn{4}{|c|}{ No./plant } & \multicolumn{3}{|c|}{ Total fresh wt/plant (kg) } & \multirow{3}{*}{\multicolumn{2}{|c|}{$\begin{array}{c}\text { Size } \\
(\mathrm{kg} / \text { fruit })^{2}\end{array}$}} \\
\hline & \multirow[b]{2}{*}{${ }^{-1}$ soil) } & \multicolumn{7}{|c|}{ Harvest } & & \\
\hline & & & 1 & 2 & 3 & 1 & 2 & 3 & & \\
\hline Control & & 3.2 & & 8.8 & 11.9 & 2.3 & 7.1 & 11.8 & 0.99 & \\
\hline & & 3.7 & & 9.9 & 14.9 & 3.2 & 9.3 & 15.1 & 1.01 & $(2 \%)$ \\
\hline 6.0 & & 3.1 & & 8.3 & 12.1 & 2.5 & 8.4 & 14.2 & 1.17 & $(18 \%)$ \\
\hline $6.0 \times 10^{-1}$ & & 3.6 & & 9.2 & 13.7 & $3.3^{*}$ & 9.2 & 15.0 & 1.09 & $(10 \%)$ \\
\hline $6.0 \times 10^{-2}$ & & 3.9 & & 10.7 & 13.6 & $3.4^{*}$ & $10.0^{*}$ & $16.6^{*}$ & 1.22 & $(23 \%)$ \\
\hline $6.0 \times 10^{-3}$ & & 3.4 & & 10.4 & 13.4 & 3.0 & $9.7^{*}$ & $16.7^{*}$ & 1.25 & $(26 \%)$ \\
\hline $6.0 \times 10^{-4}$ & & 3.1 & & 9.9 & 12.2 & 2.5 & $9.7^{*}$ & $16.5^{*}$ & 1.35 & $(36 \%)$ \\
\hline $6.0 \times 10^{-5}$ & & 3.1 & & 9.7 & 13.9 & 2.9 & 9.5 & $16.6^{*}$ & 1.19 & $(20 \%)$ \\
\hline
\end{tabular}

${ }^{2}$ Figures in parenthesis indicate percent-increase over control.

* Means significantly different from control at $P=0.05$, according to Dunnett's test.

treatment upon the cumulative third harvest.

'Royal Windsor' watermelon. During the first harvest, $6 \times 10^{-2} \mathrm{mg} \mathrm{L-TRP} / \mathrm{kg}$ soil was the only treatment that yielded more fruit than the control (217\% increase) (Table 1). However, there were no significant difference; in the number of fruit during the second and third harvests, although the same LTRP treatment $\left(6 \times 10^{-2} \mathrm{mg} \cdot \mathrm{kg}^{-1}\right.$ soil $)$ increased the number of fruit by $58 \%$ and $39 \%$, respectively, over the controls. Regression analysis excluding the control revealed a significant negative linear correlation $(r=$ $0.763 *$ ) between $\log [\mathrm{L}-\mathrm{TRP}]$ and the cumulative number of fruit at the third harvest.

There were considerable differences in the cumulative weight of the harvested melons upon treatment with L-TRP, particularly at $6 \times 10^{-5} \mathrm{mg} \cdot \mathrm{kg}^{-1}$ soil (Table 1). The yield increase in the total fresh weight was enhanced as much as $235 \%$ (first harvest), $93 \%$ (second harvest), and $80 \%$ (third harvest) upon various concentrations of L-TRP applied. During the third harvest, the lowest L-TRP concentration $\left(6 \times 10^{-5} \mathrm{mg} \cdot \mathrm{kg}^{-1}\right.$ soil $)$ significantly promoted the cumulative weight of the melons compared to the control. There was a significant negative linear correlation $\left(r=0.893^{* *}\right.$ ) between $10 \mathrm{~g}$ [L-TRP] (excluding the control) and cumulative fruit weight. On average, the weight of each fruit per plant was greatest with $6.0 \mathrm{mg} \mathrm{L}-\mathrm{TRP} / \mathrm{kg}$ soil, being $43 \%$ greater than the control (Table 1). All L-TRP applications enhanced the average weight of the melons by $16 \%$ to $41 \%$.

'Royal Sweet' watermelon. L-Tryptophan added to soil enhanced the number of fruit per plant with this cultivar from $3 \%$ to $64 \%$ (Table 2). The greatest significant and consistent response was observed with the application of $6 \times 10^{-5} \mathrm{~L}-\mathrm{TRP} / \mathrm{kg}$ soil. With each successive harvest, there was $127 \%$, $74 \%$, and $49 \%$ more fruit upon treatment with $6 \times 10^{-5} \mathrm{~L}-\mathrm{TRP} / \mathrm{kg}$ soil than for the control for the first, second, and third harvests, respectively. However, regression analysis showed no relationship between the L-TRP concentration applied and the number of fruit per plant.

The enhancement in cumulative weight of melons upon treatment with $6 \times 10^{-5} \mathrm{mg}$ L-TRP/kg soil was $168 \%$ (first harvest), $107 \%$ (second harvest), and 58\% (third harvest) greater than the control. The cumulative weight of the fruit was significantly enhanced during the second harvest at the application rates of $6 \times 10^{-5}$ to $6 \times 10^{-3} \mathrm{mg}$ L-TRP/kg soil. During the third harvest, the lowest concentration $\left(6 \times 10^{-5} \mathrm{mg} \mathrm{L}-\mathrm{TRP} /\right.$ $\mathrm{kg}$ soil) had a significant positive effect compared with the control. There was a significant negative linear relationship $\left(r=0.756^{*}\right.$ between $\log$ [L-TRP] (excluding the control) and the cumulative fruit yield. The average weight of each 'Royal Sweet' melon was increased up to $27 \%$ with the optimum concentration of L-TRP being $6 \times 10^{-3} \mathrm{mg} / \mathrm{kg}$ soil (Table 2).

'Top Score' muskmelon. Although there were no significant differences in the number of muskmelon upon the application of L-TRP, compared to the control, $6 \times 10^{-2} \mathrm{mg} \mathrm{L}-$
TRP/kg soil enhanced the number of fruit per plant during the first (22\%) and second (22\%) harvest (Table 3). The numbers continued to increase during the third harvest with $60 \mathrm{mg}$ L-TRP/kg soil giving the overall greatest yield (25\% increase relative to the control).

The cumulative fresh weight was significantly increased upon a L-TRP treatment of $6 \times 10^{-2}$ and $6 \times 10^{-1} \mathrm{mg} \cdot \mathrm{kg}^{-1}$ soil during the first harvest. The effect of L-TRP on muskmelon yield was even more pronounced during the second and third harvest. Application rates of $6 \times 10^{-5}$ to $6 \times 10^{-2} \mathrm{mg}$ L-TRP/kg soil significantly increased the yield in weight as much as $42 \%$. A significant negative linear correlation $\left(r=0.762^{*}\right)$ was found between the cumulative fruit yield at the third harvest and $10 \mathrm{~g}$ [L-TRP] (excluding the control). The average weight of each 'Top Score' fruit was enhanced by all L-TRP applications (Table 3). The fruit weight was increased $36 \%$ upon the addition of $6 \times 10^{-4}$ $\mathrm{mg} \mathrm{L-TRP/kg} \mathrm{soil.}$

The increase in yield of melons may be attributed to the fact that TRP is a precursor of auxins. The plant response appears to be hormonal since the lower concentrations of TRP $\left(6 \times 10^{-5}\right.$ to $6 \times 10^{-3} \mathrm{mg} \mathrm{L}-\mathrm{TRP} / \mathrm{kg}$ soil) had the most pronounced effect on the number and weight of melons produced. Tryptophan serves as precursor of auxin biosynthesis both in plants and microorganisms. Frankenberger and Brunner (1983) have demonstrated the synthesis of TRP-dependent auxins (indole-3-acetamide and IAA) in soil as a result of microbial action. The effect of TRP on melons could be attributed to substrate-dependent auxin production either endogenously synthesized within the plant after direct uptake of TRP and/or derived as a microbial metabolize and exogenously supplied to the plant. The possibility that plant growth regulators released as microbial metabolizes in the soil can affect plant growth has recently been reviewed by Arshad and Frankenberger (1990b). Previous studies have demonstrated that the application of precursors of various plant growth regulators such as TRP (an auxin precursor), adenine + isopentyl alcohol (cytokinin precursors), and L-methionine and L-ethionine (ethylene precursors) to soil or sand can affect the growth of Douglas fir, radish, corn, and tomato, respectively (Arshad and Frankenberger, 1990a; Frankenberger and Poth, 1987b; Nieto and Frankenberger, 1990).

L-Tryptophan was applied as a soil drench at the seedling stage. There was no vegetative growth response evident before transplanting into the field. The plant response was noted only in fruit yield. The resulting product of L-TRP metabolism via soil microflora or the plant itself may have involved the conversion of auxins into a storage form such as a conjugate and activated upon the reproductive stage. Several studies have revealed that auxin conjugates are synthesized in plants when auxins are applied to plant roots (Iversen et al., 1971; Kendall et al., 1971; Morris et al., 1969).

In the previous summer (1986), attempts were made to add a solution of L-TRP to the 
melon seedlings of the same cultivars established in the field. There was no significant difference between the control and L-TRPtreated plants with this type of application. This lack of response might be due to leaching of the TRP and/or adsorption to a large volume of soil, leading to little or no uptake of TRP and/or its metabolizes by the seedling roots. Yield was significantly increased only when L-TRP was contained within the soil matrix and the seedlings were temporarily limited in space for root proliferation, forcing the uptake of L-TRP and/or metabolizes (e.g., auxins) before transplanting to the field.

The application of L-TRP as an agrochemical to seedling transplants could provide substantial economic returns to the melon industry. Fruit size was increased up to $43 \%$ for watermelons and $36 \%$ for muskmelons upon treatment with L-TRP to soil over their respective controls. However, further research is needed to investigate the effect of TRP treatment on the nutritional quality of the watermelons and muskmelons.

\section{Literature Cited}

Arshad, M. and W.T. Frankenberger, Jr. 1990a. Response of Zea mays and Lycopersicon esculentum tothe ethylene precursors, L-methionine and L-ethionine applied to soil. Plant and Soil 122:219-227.

Arshad, M. and W.T. Frankenberger, Jr. 1990b. Microbial production of plant growth regulators. In: B. Metting (cd.). Soil microbial technologies. Marcel Dekker, New York. (In press.)

Dannenburg, W.N. and J.L. Livennan. 1957. Conversion of tryptophan $-2^{14} \mathrm{C}$ to indoleacetic acid by watermelon tissue slices. Plant Physiol. 32:263-269.

Erdmann, N. and U. Schiewer. 1971. Tryptophan-dependent indoleacetic acid biosynthesis from indole, demonstrated by double labelling experiments. Planta 97:135-141.

Frankenberger, W. T., Jr., and W. Brunner. 1983. Methodofdetectionofauxin-indole-3-aceticacid in soils by high performance liquid chromatography. Soil Sci. Soc. Amer. J. 47:237-241.

Frankenberger, W. T., Jr., and M. Poth. 1987a. Determination of substituted indole derivatives by ion suppression-reverse phase high performance liquid chromatography. Anal. Biochem. 165:300-308.

Frankenberger, W.T., Jr., and M. Poth. 1987b. Biosynthesis of indole-3-acetic acid by the pine ectomycorrhizal fungus Pisolithus tinctorius. Applied Env. Microbiol. 53:2908-2913.

Frankenberger, W.T., Jr., and M. Poth. 1988. LTryptophan transaminase of a bacterium isolated from the rhizosphere of Festuca octoflora (Graminae). Soil Biol. Biochem. 20:299-304.

Frankenberger, W.T., Jr., A.C. Chang, and M.
Arshad. 1990. Response of Raphanus sativus to the auxin precursor, L-tryptophan applied to soil. Plant and Soil 129:235-241.

Iversen, T.-H., T. Aasheim, and K. Pedersen. 1971. Transport and degradation in relation to geotropism in roots of Phaseolus vulgaris. Physiol. Plant. 25:417-424.

Kendall, F. H., C.K. Park, and C.L. Mer. 1971. Indole-3-acetic acid metabolism in pea seedings, a comparative study using carboxyl- and ring-labelled isomers. Ann. Bet. 35:565-579.

Lehninger, A.L. 1975. Biosynthesis of the aromatic amino acids. Biochemistry. 2nd ed. Worth Publishers, New York. p. 708-710.

Meister, A. 1965. The role of amino acids in nutrition. Biochemistry of the amino acids. vol. L Academic, New York. p. 201-230.

Morris, D. A., R.E. Briant, and P.G. Thomson. 1969. The transport and metabolism of ${ }^{14} \mathrm{C}-1 \mathrm{a}-$ belled indoleacetic acid in intact pea seedlings. Planta 89:178-197.

Nieto, K.F. and W.T. Frankenberger, Jr. 1990. Influence of adenine, isopentyl alcohol and Azotobacter chroococcum on the growth of Raphanus sativus. Plant and Soil (In press.)

Steel, R.G.D. and J.H. Torrie. 1980. Principles and procedures of statistics: A biometrical approach. McGraw-Hill, New York.

Thimann, K.V. 1935. On the plant growth hormone produced by Rhizopus suinus. J. Biol. Chem. 109:279-291. 